PERGAMON International Journal of Information Management 19 (1999) 33-47

International Journal of

Information

Management

\title{
Workplace experiences of information literacy
}

\author{
Christine Susan Bruce* \\ School of Information Systems, Faculty of Information Technology, Queensland University of Technology, Gardens Point \\ Campus, 2 George Street, Brisbane, Qld 4000, Australia
}

\begin{abstract}
The idea of information literacy, broadly defined as the ability to recognise information needs and identify, evaluate and use information effectively, has been of growing concern in the education sectors for a number of years; whilst in the workplace, employers and managers have perhaps attended more to the need for computer and information technology skill. New descriptions of information literacy, that may be of value to the business sector, are now beginning to appear as a result of qualitative research into how professional employees experience the effective use of information. This paper summarises the outcomes of an investigation into the experience of information literacy amongst various types of professionals; and explores the possible differences and interrelations between individual and organisational information literacy suggested by these outcomes. Seven different ways of experiencing information literacy were identified. These experiences are closely related to important workplace processes such as environmental scanning, information management, corporate memory, and research and development; confirming that information literacy should be considered a significant part of the character of learning organisations as well as being a key characteristic of the organisation's employees. Implications of individual and organisational information literacy for beginning and continuing professional education are explored. (C) 1999 Elsevier Science Ltd. All rights reserved.
\end{abstract}

Keywords: Information; Information literacy; Information management; Corporate memory

The idea of information literacy, broadly defined as the ability to recognise information needs and to identify, evaluate and use information effectively, has been of growing concern in the education sectors for a number of years; whilst in the workplace, employers and managers have perhaps attended more to the need for computer and information technology skills. As information technology becomes more seamless and user-friendly, it is likely that attention will shift more clearly to questions of how people are actually interacting with, and using, the information which technology makes available. In organisations where users continue to struggle with information technology, the perennial need to make decisions, problem-solve and research, also suggests the need for employees to be able to deal with information per se as being of primary importance.

\footnotetext{
*Fax: + 61738641969 ; e-mail: c.bruce@qut.edu.au.
} 
Drucker (1992) discusses the need for organisations to become information literate. He suggests that corporations need to learn to ask questions such as: What information do we need in this company? When do we need it? In what form? How do we get it?; and then to ask further questions related to the impact of information received. Clearly the information required could come from anywhere, or from any person, and could appear in any medium. Questions of this kind are imperative to contemporary organisations. Why then, is the need for information literacy not being given the priority that information technology and computer literacy have achieved?

Some of the limiting factors in developing interest in information literacy include the term itself, which does not clearly communicate its meaning; the 'insufficiency' of the definitions commonly attributed to the term; the fact that the discussion is largely confined to library studies, and to a more limited extent, to the education disciplines; confusion of information literacy with computer and information technology literacy, and the lack of theoretical cogency underlying much of the literature. (Bruce, 1997; Mutch, 1997). Despite these limitations, the potential importance of information literacy to business is asserted by Mutch (1997, p. 378) in a recent paper which 'outlines how the concept might be employed within the business field'. Mutch suggests that an emphasis on knowledge, and the making of meaning, should be employed to strengthen the value of the concept, particularly in relation to the notion of 'learning organisations'.

New descriptions of information literacy, that may be of value to the business sector, as well as educators, are now becoming available from qualitative research into how professional employees experience the effective use of information. For example, Cheuk (1998) has recently shown how the information skills processes take on a recursive and multi-phase character amongst a group of internal auditors. There are three groups of people likely to be interested in workplace experiences of information literacy:

(1) Managers with a concern for staff members' professional development and ability to respond to change.

(2) Information managers with an interest in training and educating their clientele to effectively use the organisation's information services.

(3) Trainers and educators who wish to prepare learners for their chosen profession.

This paper summarises the outcomes of a phenomenographic investigation into the experience of information literacy amongst various types of professionals; investigates the possible differences and interrelations between individual and organisational information literacy suggested by these outcomes, and explores some implications for education and training. The study identified seven different ways of experiencing information literacy. These experiences are closely related to important workplace processes such as environmental scanning, information management, corporate memory, and research and development; confirming that information literacy should be considered a part of the character of learning organisations, as well as being an important characteristic of the organisation's employees.

\section{Exploring workplace experiences of information literacy}

The picture of information literacy depicted below was developed using a research approach known as phenomenography (Marton, 1994). This approach has been used extensively in higher 
education to explore qualitative variation in people's experience or understanding of important concepts or phenomena. It has also underpinned an approach to teaching and learning which emphasises the need to help learners change, or broaden, their repertoire of existing conceptions or experiences (Marton \& Booth, 1997). Phenomenography is a qualitative research approach which seeks to interpret the world as it is understood by others. It is generally used to further our understanding of how phenomena are experienced.

A 'phenomenon', in phenomenography, is defined as the combination of different ways in which an aspect of the world is conceived or experienced, while each different experience, or conception, is described as a relation between individuals and some 'object' with which they interact. Thus each of the seven ways of experiencing information literacy described in the next section, represents different ways in which people interact with information; the seven different experiences, taken together, represent the 'phenomenon' of information literacy.

Four types of professionals, mainly from Australian universities, participated in the study. First, there were librarians and IT professionals; second, there were counselling services staff; third, there were staff developers; and fourth, there were academics. The academics came from professional disciplines including engineering, music, business and architecture. Some of these people were also involved in managerial and consulting roles; all of them would fall into the category of 'knowledge workers', their 'workplaces' being various organisational units in higher education institutions. Altogether, more than 60 individuals contributed; 16 through semi-structured interviews and the rest by supplying written data either during workshops or via electronic mail.

When discussing information literacy during interviews, participants were asked to focus on their experiences of information literacy - or trying to be information literate - at work. Their reflections were often broadened to include descriptions of people whom they considered to be information literate, either colleagues, family or friends. In this way concrete examples of the experience of information literacy were obtained to form the basis of data analysis. Complete details of the research process are available in The Seven Faces of Information Literacy (Bruce, 1997) which documents the empirical study summarised here.

\section{Seven faces of information literacy in the workplace}

The different experiences of information literacy encountered in participants' workplaces reveal a distinctive picture of the phenomenon that is characterised by:

- Varying emphases on technology;

- Emphasis on the capacity to engage in broad professional responsibilities, rather than specific skills;

- Social collaboration or interdependence between colleagues, rather than an emphasis on individual capability;

- Need for the partnership of information intermediaries;

- Emphasis on intellectual manipulation of information rather than technical skill with IT.

The descriptions summarising the research outcomes which follow have been constructed to demonstrate something of how knowledge workers practice information literacy in their contexts. Some of the examples come from people describing their own experience, others capture their 
observations and reflections about colleagues. The descriptions reveal the multi-faceted nature of the phenomenon.

Each of the seven faces, or different ways of experiencing information literacy is made up of three key elements. Two of these elements, information technology and information use, are present in all the categories, or ways of experiencing. The third element changes in each category, lending a uniqueness which makes that category distinctive. While each face is distinctive, individuals are likely to use more than one approach depending upon the situation in which they find themselves. Some people may have personal experience of a limited number of the faces. Those who have achieved a high level of information literacy would be equipped to select the most appropriate approach to implement from the whole range.

To support my descriptions of the seven faces, I have depicted the three parts, using circles, to show which element is in the foreground of information users' awareness and which is in the background. Close attention to these 'awareness structures' reveals that information technology $(B L A C K)$ moves from being the centre of attention in the first category, to the background in the last categories. Information use (GREY) shifts from being in the background in the first category, to being central in the later categories.

\subsection{The first face: information literacy is experienced as using information technology for information} awareness and communication (Fig. 1)

In this category information technology helps users to stay informed and to communicate with colleagues within the organisation and across the globe. The following researchers reveal something of this experience:

These days there is a standard set of electronic tools (within the technical university sector anyway) that everyone (all competent people) uses to a greater or lesser extent ... Periodically I run CD-ROM searches of a few relevant databases. But mostly these are looking for something specific. At these times I generally throw in a few general searches anyway just to see. Sometimes I just browse the Internet using the package MOSAIC which can now browse

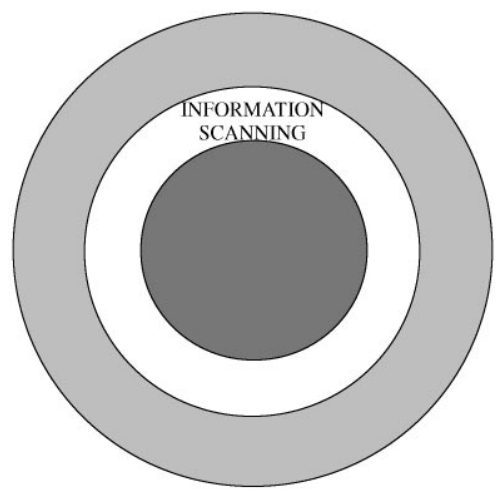

Fig. 1. The IT-info scanning-Conception [Black = IT; Grey = information use]. 
and search WWW and gopher sites and then retrieve files using FTP. Often I come across interesting information and can keep up with the developments.

In response to a request for a definition of an information literate person came the reply:

Well, it's anyone but me. It would be someone who could come in and switch on to the world over there (waving at the PC in the room) and really engage in wonderful trans-Atlantic conversations... It would be someone who thought they'd go down for half an hour to the library bottom floor and just play around with the indexes $(C D-R O M s)$, see what they could find. It would be someone who used all kinds of modem things..

It seems that experiencing information literacy as using IT, and being able to do so successfully, means recognising that this is not a solitary experience. Keeping up with IT involves being part of a community, each member of which assists others:

It is hard in isolation. You need people to help. Then everyone becomes expert in slightly different aspects and is available to help and teach the others.

\subsection{The second face: information literacy is experienced as finding information from appropriate} sources (Fig. 2)

In this category, knowledge of information sources is important - including organisational, human, computer and print sources. People emphasise the need to lean on information professionals to help speed the process.

I don't think that people have time to sit down and learn every new package that comes out, and I think that you should be able to use the personnel that have that experience. [For example] I got quite a lot of help from our librarian in terms of looking for new books in the field ... you could probably spend a day trying to do that yourself, for instance.

What can I recall that I might have seen which might be interesting? ... you get to know the materials that are available and the sources and the journals in which that material will be.

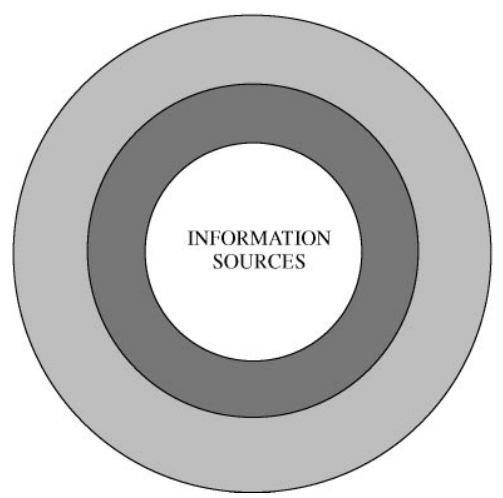

Fig. 2. The information sources conception. 
..... it's simply getting to know the resources, getting to know the library that you've got at hand ... so that you can go instantly to the library and in many cases, without ever having to go to the catalogue, you can identify what you need.

Knowing a human or organisational source is a direct substitute for knowing the print or electronic source. What is critical is knowing whom to ask: "If I can think quickly of a colleague who's done that or who knows someone else, that's the way I think engineers work."

\subsection{The third face: information literacy is experienced as executing a process (Fig. 3)}

This category features information processes. It is intricately bound up with the experience of problem solving or decision-making. The information processes themselves are not straight forward. They are regarded by some as a creative art being implemented differently by different people in different contexts.

... any of us would be able to tackle a new problem which we've had no past knowledge of, and be able to chase it up and follow it through. For example, a colleague was asked to provide some advice about [an engineering structure]. He'd never looked at that type of structure before in his life, but he was able to chase it up, and find out the structural implications of what was going on and discuss it with the rest of us.

The first thing has to be to define what the problem area is ... so an effective information user will be able to narrow down the problem. Having narrowed down the problem that would lead to, or would provide an indication that there needs to be more information gathered in certain areas around that problem; so the effective information user would be able to identify where the additional information is needed or where the gaps are. I guess a small but vital part of it is to be able to gather that information from whatever sources are available and to analyse it; and then based on that make a decision or solve the problem or whatever ... It's almost like basic problem-solving techniques.

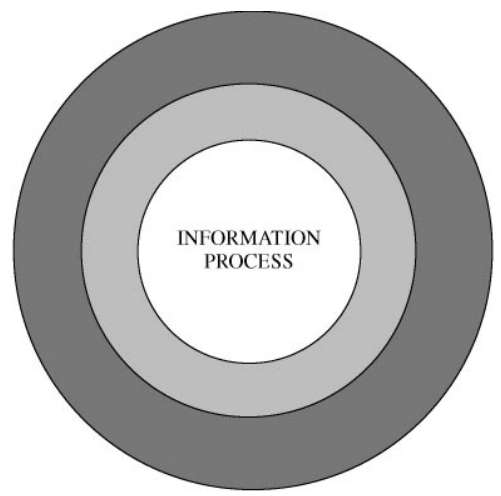

Fig. 3. The information process conception. 


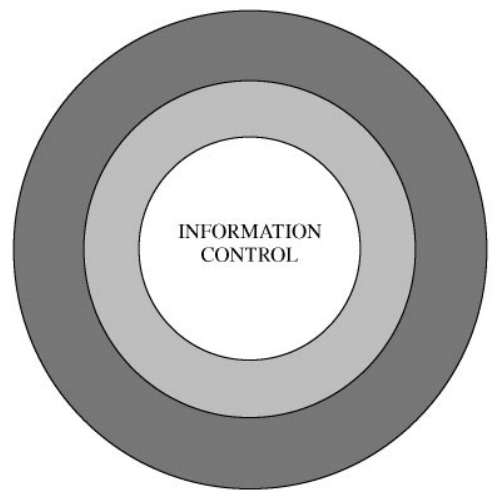

Fig. 4. The information control conception.

\subsection{The fourth face: information literacy is experienced as controlling information (Fig. 4)}

In this category people are focussing on bringing relevant information within their personal sphere of influence and managing it in such a way that it is retrievable. This category is about making connections between information, projects and people using mechanical tools (such as cards of files), electronic tools or the human brain. Projects being undertaken influence the structure of organisation. In this way links are created between items of information and particular aspects of the project:

... it relates to $\mathrm{x}$, or something, so I stick it in the file and it's there if I need it... when we had massive amounts of stuff to process, and I consider we did that very effectively,... I thought: 'we need to get a piece of information from a particular organisation.' I rang them up and I said 'please send me that report' which they did. I read it ... put it in the right file, then when that part of the report was being written, I took it out of the file and used it.

What makes him competent is what he's got in his ruddy head. He knows. He's seen something there, 1968 somebody said that, and he knows, and he knows where to go and get it...Well, ... somehow he has the sort of brain that he can use as a filing cabinet which I can't do. I use my filing cabinet as my brain. His things are filed in his brain and he knows exactly where to get them ... it's a reverse process.

One of the reasons she is an effective information user is that.... she seems to be able to remember people, to remember what they are doing, to have a life story attached to each person she ever meets. It's because she's linking the information to a person, and that helps somehow to access the information. So that when a topic comes up, she not only has in a sense one reference point, she has two, and they are linked, so that she is able to retrieve that information. ... a number of times when things come up she'll say 'so and so would be a good source of information on that', or 'you could go and ask so and so because that person did such and such'. 


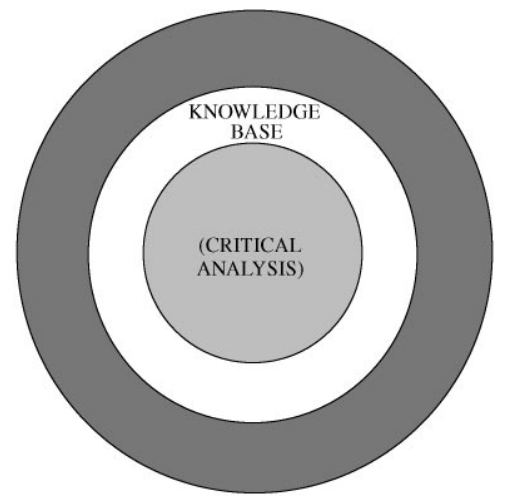

Fig. 5. The knowledge construction conception.

2.5. The fifth face: information literacy is experienced as building up a personal knowledge base in a new area of interest (Fig. 5)

Here learning, in the sense of building up a knowledge base is the user's purpose. This involves the development of personal perspectives about the knowledge gained and is wholly dependent on critical thinking or analysis.

Well, I read a book because I'm interested in the topic and the book might have a very useful quote from another author. I then turn to the back of the book and find the reference and then I go to the library catalogue and look it up, order it, get it off the shelf, read it, in turn, that will refer me on to yet another bibliography at the back of another book and so on and so on .... at the end of that process, if I find I still have holes in the information that I've gathered and that I need to go further, then is when I would consult the indexes that would tell me all the other things that are available and which might be of interest, and I'd access which ones of those I thought would be of use.

... What's happening in the process is that I'm able to say, 'oh, well he says that about it because of the way he's approaching the subject or because of his previous experience or his expertise in that particular area of the field. She's approaching it from here. Where do I stand in relation to those two? I prefer that way of looking at it'. OK. So I'll follow some of that person's references rather than, I know the sort of vibes or prejudice or whatever this person is going to bring to it, and I'm not really interested in that ... It's a fairly selective way of doing it but at the same time you remain aware of both prongs of the fork if you like...

... here's your topic, salami technique, you know, slice it up into little bits, do each little bit so that it's not overwhelming ... all that sort of stuff ... but my own personal style would be over reading, over gathering, but I'm not an instrumental task-oriented person, I'm a more intuitive, reflective type person. Maybe that information style suits me. ... I want to ... flip around a bit ... the 'cast-the-net-and see-what's-out-there' approach. 


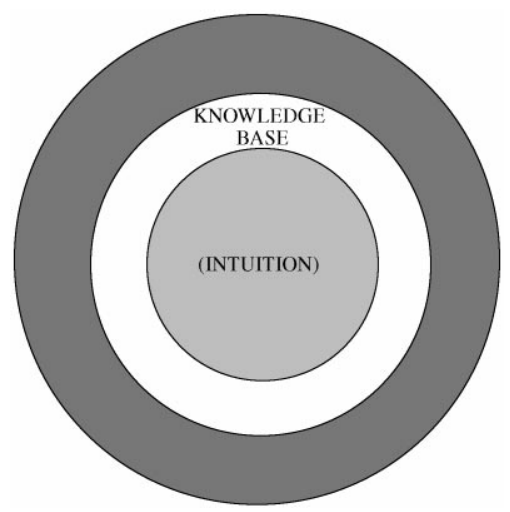

Fig. 6. The knowledge extension intuition-conception.

2.6. The sixth face: information literacy is experienced as working with knowledge and personal perspectives adopted in such a way that novel insights are gained (Fig. 6)

This sixth experience is grounded in extensive personal knowledge and experience together with a capacity for creative insight or intuition. It remains mysterious to those who experience it, but they are highly dependent on insights to develop new forms of knowledge, new approaches to tasks or novel solutions.

He has an idea, so the creative thought ... he does lots of literature surveys, has a look to see what the literature surveys suggest and then he would try and research to try and find out how close the literature source is to the experience in business ..., so it's a new creative thought. So he uses information to create more information.

... it actually involves new information. Actually being able to bring a new perspective, something that has never been done before, to either extend an argument beyond where anybody has ever extended it, see something in a totally different light...

... it's a subconscious thing that's built up from experience over time. You get this sort of funny feeling......things have come to me as a flash. ... after peering in the screen for some hours you get very ..., blow this, I'm going to go and lie down.' So I did. And then suddenly I jump up with this great inspiration and rush down and pound the keyboard. You don't ... no idea (how). Subconscious sort of says 'do these things'.

I don't think you need to be technologically literate provided you have other sources of gathering that information which may be using people who are technologically literate. Yes. I don't think it's an essential ingredient for the individual but it sure makes it easier ... I'm sure there must be plenty of people who are quite computer illiterate who are good information users. I mean, it surely enables one to be able to do it much more quickly than without it. If you're relying on not being able to use modern computer techniques, I think you can do it, but it'll take a long, long time, much, much longer. 


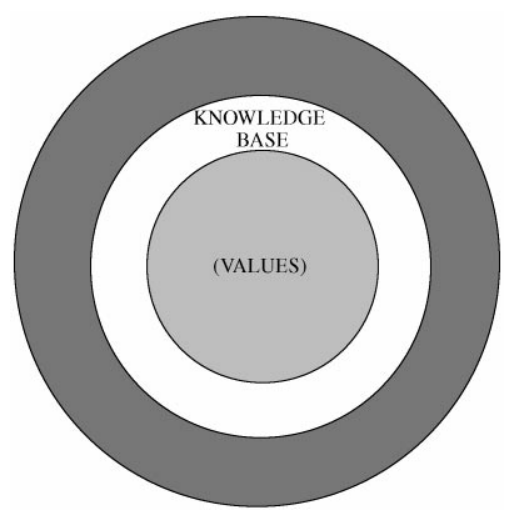

Fig. 7. The wisdom conception.

2.7. The seventh face: information literacy is experienced as using information wisely for the benefit of others (Fig. 7)

A personal quality of wisdom is brought to this experience of information use. A consciousness of personal values and ethics is combined with an individual's knowledge and experience when working with others.

Accessing information doesn't really come into it ... I would like to think the information is not simply utilitarian ... there's some kind of wisdom in the way it's used ... people have values and those values are brought to the using of information. We all have larger responsibilities and have values which we may or may not be aware of at the time, but they inform a lot of what we do, whether it is in our work or in our personal relationships ... and that I see as the kind of ethical domain of our lives. Information should remain subservient to that rather than being the goal in itself.

New information is not created as in the previous category; rather it is used to the benefit of the information user, colleagues or clients:

... she knows the best way to be able assist those people. ... she works in a public contact job where what she knows has an impact on what happens in those people's lives... So the decisions that she makes about people in her job actually affects, has an effect on their lives.

Another example comes from a description of counselling clients in a sexual harassment case. The interviewee explains the situation as one in which his knowledge indicates that the case should be reported. His experience of the larger context of such situations, however, indicates that this would not be a wise option:

... is there any point in the person actually telling anyone about it? ... it may be an option and it may be that it would be the thing to do, but it is not necessarily a wise thing to do in terms of the pain involved. 


\section{Individual and organisational information literacy?}

Are these ways of experiencing information literacy likely to be relevant in other contexts? If the higher education environment, with its information rich and technologically sophisticated infrastructures, could be regarded as a 'model', in some respects, for the practice of knowledge workers, then it is likely that the experiences found in this study will be shared, at least to some extent, by professionals in other organisations. The various experiences can also be linked to key information rocesses in the workplace, providing further evidence that the seven faces would be generalisable to situations other than educational institutions. Table 1 shows the relationship between these corporate processes and the seven faces of information literacy.

Correspondence between the various faces and these workplace processes, suggests that the faces are useful constructs for beginning to interpret the meaning of information literacy in professional practice at the level of organisational, as well as individual, experience. The relationships between workplace processes and the seven faces also firmly establish information literacy as an important part of the character of 'learning organisations', as well as of 'life-long learners'. This link is supported by the descriptions of information literacy which reveal the importance attributed to the phenomenon, by participants, for maintaining currency, networking, problem-solving and maintaining a client-orientation. The importance of information literacy to learning organisations is also visible in descriptions of these entities, such as the following, which include a focus on critical thinking and learning-to-learn:

A learning organisation is an organisation with a well-developed capacity for double-loop learning (goal-based learning and learning through critical questioning); where there is ongoing attention to learning how to learn; and where key aspects of organisational functioning support learning (Field and Ford, 1995).

We could infer, then, that in the workplace, information literacy can be considered at both an individual or work-team, and an organisational level. It is likely that, at an individual and possibly at a work-team level, experiences of information literacy would resemble those identified in this paper; whereas at an organisational level they would be subject to a higher degree of formalisation and structuring. Further, it would be easier for individuals and work-teams to engage in the practice of information literacy if corresponding organisational processes were in place which

Table 1

Workplace processes that correspond to the seven faces of information literacy

The seven faces of IL [Individual]

The information technology experience The information sources experience The information process experience The information control experience The knowledge construction experience The knowledge extension experience The wisdom experience
Workplace processes [Organisational]

Environmental scanning

Provision of inhouse and external information resources and services Information processing; packaging for internal/external consumption Information/records management, archiving

Corporate memory

Research and development

Professional ethics/codes of conduct 
encouraged and supported such practice. Most importantly, if the staff of learning organisations are necessarily life-long learners, then they are also necessarily information literate.

Both the individual faces of information literacy, and the corresponding workplace processes, suggest that senior staff of organisations need to be acquainted with the character and value of information literacy at the two levels. Awareness of the importance of information literacy to the future of the organisation would help to ensure that priority is given, when planning and budgeting, to establishing and maintaining information services, and to professional development programs for staff where appropriate.

\section{Information literacy in education and training programs}

The seven faces of information literacy, and their corresponding workplace processes, provide a curriculum framework for information managers with an interest in training and educating their clientele to effectively use the organisation's information services, and for providers of beginning and continuing professional education. Understanding more about how information is effectively utilised by practising professionals is likely to help educators design curriculum which is relevant and transferable to professional practice. The ways in which information literacy is experienced in the world of work should influence how it is taught and experienced in professional education and professional development programs.

The 'Seven Faces of Information Literacy Model' is likely to be most influential if curriculum is used to:

- diagnose the existing range of learners' information literacy experiences;

- deepen those experiences with which they are familiar; and

- usher them into previously unfamiliar experiences.

Ideally, the end result of information literacy education would be people with experience of all seven faces. They would be able to select the most appropriate face to draw upon in a new situation.

Such an emphasis would be consistent with approaches to teaching and learning that (1) interpret learning as coming to experience and understand the world differently, rather than as retaining information about the object of study (Marton \& Booth, 1997; Marton et al., 1996); and (2) interpret competence as experiencing practice in particular ways, rather than mastering skills or knowledge which may have a short shelf-life (Dall'Alba \& Sandberg, 1996; Velde \& Svenssen, 1996).

Following from the experiential model of information literacy presented here, learning information literacy can be described as coming to experience the effective use of information in new, and increasingly complex, ways; and teaching information literacy can be described as facilitating this change. For trainers and educators, this means that the seven faces of information literacy suggest some new directions in information literacy education, and also reaffirm some existing approaches.

\subsection{New directions suggested by the Seven Faces model}

New directions in information literacy education suggested by the 'Seven Faces' model include the need to: 
1. Find ways to help learners access/experience for themselves these various faces of information literacy. This will mean designing learning tasks that systematically incorporate all, or a selection, of the faces. They need to decide, for any one area of learning, whether students should focus on all aspects of the phenomenon, or on a subset of the faces.

2. Find ways to help learners reflect on their use of information, so that they become aware of their experiences and transfer these ways of working to a wide range of situations. This would mean familiarising learners with the range of experiences of information literacy, and using strategies such as journalling (diary-keeping) or discussion to help them explicitly consider their own information behaviour in relation to the seven faces model.

3. Emphasise the social/interdependent nature of information literacy as experienced by users. This experience is contrary to the individualistic approach often promulgated. For example, learning to use information sources or electronic technologies should not mean that students be expected to master all the tools at their disposal. Rather they should be able to use whatever is required with the assistance of peers and available support services. They should learn to value the information provision role of information intermediaries, and learn to discern when it would be appropriate to use the services of an information professional.

4. Acknowledge the importance of these experiences of information literacy in developing or endorsing professional curricula. Perhaps curricula could be matched against the seven faces of information literacy to establish that each of the faces is adequately represented. This would help find and resolve important gaps.

5. Explore the ways in which organisational information processes can support the experience of individuals and workteams.

\subsection{Affirmation of existing trends}

The model also confirms some existing trends, suggesting that curriculum designers and teachers or trainers should:

6. Continue to emphasise conceptual skill and intellectual agility more than information technology or information location skills. This is not to say that information technology should be dismissed, it forms a part of each experience of information literacy. However, it is only focal in the first experience, in most of the others conceptual skills are of greater importance. In the information process experience, identifying an information need, for example, is a conceptual skill; in the information control experience, structuring information and making connections between new information and projects (finding relevance) are conceptual skills.

7. Remember that training people to use various forms of software packages or technologies does not constitute information literacy education; teaching information sources is also only one facet of information literacy education. It is enabling people to experience information literacy in the ways described earlier that constitutes information literacy education. IT and specific sources are, at best, pre-requisites (as in the information technology and information sources experience) and, at worst, irrelevant (as in the knowledge extension and wisdom experiences). 
8. Teach technology so that people become comfortable with adopting and adapting to change, rather then requiring their attendance at a never-ending flow of training programs.

The first two directions stem from an approach to teaching and learning described as 'relational', or sometimes as 'phenomenographic pedagogy'. It is an approach which focuses on the need to understand variation in people's experience of phenomena in order to help them broaden or change that experience (Marton \& Booth, 1997). The 'seven faces' described here provide a model of information literacy which is compatible with the relational approach to teaching and learning. Many of these directions would also be easily incorporated into frameworks such as reflective practice (Schon, 1987), action-learning (Revans, 1982) and action-research (Zuber-Skerrit, 1992). Merging information literacy education with frameworks such as these, which have already proven themselves desirable for professional education, would create curriculum models highly relevant to professional practice.

For professional courses to prepare graduates to take their places in learning organisations, educators need to consider whether their curriculum explicitly provides opportunities for students to:

- use information technology for information awareness and communication;

- come to know a range of relevant bibliographic, human and organisational information sources;

- develop personal heuristics for the application of information processes;

- control information through establishing and mapping or formalising relevant connections;

- adopt a critical approach to knowledge construction;

- exercise their intuitive capacities to gain new insights or understandings;

- draw upon personal values/ethics when using information.

Once curriculum achieves the above, educators need to also design strategies for helping students to (1) be aware of these learning opportunities, (2) reflect upon their work in this area and (3) recognise that coming to grips with these aspects of information use is an integral part of their professional development and growth. In short, educators need to help learners experience information literacy in professional courses in ways that are consonant with the experience of information literacy in professional practice.

\section{Conclusion}

Information literacy is about peoples' ability to operate effectively in an information society. This involves critical thinking, an awareness of personal and professional ethics, information evaluation, conceptualising information needs, organising information, interacting with information professionals and making effective use of information in problem-solving, decision-making and research. It is these information based processes which are crucial to the character of learning organisations and which need to be supported by the organisation's technology infrastructure. To date, using the phenomenographic research approach has made available descriptions of seven qualitatively different ways in which information literacy is experienced. The experiences are 
closely related to information based workplace processes and suggest a range of implications for professional education and development.

\section{Acknowledgements}

A complete report of the empirical study summarised in this paper is available in Christine Bruce (1997) The Seven Faces of Information Literacy, AUSLIB Press, Adelaide [auslib@mail.camtech.net.au]. An earlier version of this paper, 'Information literacy in the workplace', was presented to the Third Australian Information Literacy Conference, Canberra, 8-9 December 1997. I am grateful to the conference committee for encouraging me to consider the implications of the empirical study for information literacy in the workplace.

\section{References}

Bruce, C.S. (1997). The Seven Faces of Information Literacy. Adelaide: Auslib Press.

Cheuk, B. (1998). An experienced based information literacy model in the workplace: case studies from Singapore. In D. Booker (Ed.), Information Literacy: The Professional Issue. Proceedings of the 3rd Australian National Information Literacy Conference, Canberra, 1997, (pp. 74-82). Adelaide: University of South Australia Library.

Dall'Alba, G., \& Sandberg, J. (1996). Educating for competence in professional practice. Instructional Science, 24(6), 411-437.

Drucker, P. (1992). Be data literate - know what to know. The Wall Street Journal, 16.

Field, L., \& Ford, B. (1995). Managing Organisational Learning: From Rhetoric to Reality (p. 24). Melbourne: Longman.

Marton, F. (1994). Phenomenography. In T. Husen, \& N. Postlethwaite (Eds.), International Encyclopedia of Education (pp. 4424-4429). Oxford: Pergamon.

Marton, F., \& Booth, S. (1997). Learning and awareness. New York: Lawrence Erlbaum and Assoc.

Marton, F., Hounsell, D., \& Entwistle, N. (Eds.). (1996). The Experience of Learning. (2nd ed.). Edinburgh: Scottish Academic Press.

Mutch, A. (1997). Information literacy: an exploration. International Journal of Information Management, 17(5), $377-386$.

Revans, R. (1982). The Origins and Growth of Action Learning. Lund: Studentlitteratur.

Schon, D. (1987). Educating the Reflective Practitioner: Toward a New Design for Teaching and Learning in the Professions. San-Francisco: Jossey-Bass.

Velde, C., \& Svensson, L. (1996). The conception of competence in relation to learning processes and change at work. Paper presented at the 4th Conference on Learning and Research in Working Life, Steyr, Austria, 1-4 July 1996.

Zuber-Skerritt, O. (1992). Action Research in Higher Education: Examples and Reflections. London: Kogan Page.

Christine Bruce (BA, Grad Dip Lib Sc, M.Ed (Res), Ph.D., AALIA) is a lecturer in the School of Information Systems at the Queensland University of Technology, Australia. Christine chairs the Faculty of Information Technology Teaching and Learning Committee and is Associate Director of the Information Systems Management Research Concentration. Her research interests revolve around the experienced worlds of information and IT users. 